\title{
Sweet Crush: A Multimedia Virtual Heritage Portrait of the North Queensland Sugar Industry
}

\author{
David Salisbury
}

James Cook University

\begin{abstract}
The sugar industry underpins the economic and social fabric of a cross section of North Queensland. The aim of this paper is to recontextualize the ambient sounds and visual narratives embedded within the crushing process. This study demonstrates to workers and the wider community, undiscovered meaning in these everyday events.
\end{abstract}

$\mathrm{I}_{\mathrm{i}}^{\mathrm{n}}$ 2007 Clive Hutchinson and I received a faculty grant to investigate the sugar industry in North Queensland. After contacting several of the sugar mills in North Queensland we got a positive response from the mill at South Johnstone. We made the appropriate preparations and scheduled an appointment with Phillip Miskin the general manager of the south Johnstone mill. When we arrived we were given a thorough safety induction and the necessary protective gear including goggles, hard hats and bright orange vests. Mr. Miskin then gave us a comprehensive tour of the mill.

Over the next couple of days Clive took hundreds of photographs and I digitally recorded hours of sounds that the mill produced. This data was ultimately combined in a new media video project we called "Sweet Crush" and was featured as an exhibition at Umbrella Studio Contemporary Arts from 4 April - 11 May 2008 and in the 2008 Queensland Festival of Photography. This paper is an autoethnographic account of the process involved in collecting the data and recasting that information in a creative output and how this represents the sugar industry in particular the South Johnstone mill and surrounding region.

\section{Definition of Key Terms:}

New Media in the context of "Sweet Crush":

In the book New Media: a critical introduction, the authors outline six kinds of new media four of which apply here:

1. New textual experiences

2. New ways of representing the world

3. New relationships between subjects

4. New experiences of the relationship between embodiment, identity and community (Lister 2009)

1) New textual experiences has to do with ways in which we consume types of media and entertainment which in the case of Sweet Crush was a multimedia art exhibition that included a projected video photographic montage on a large screen via computer 
and data projector, an amplified soundtrack and framed photos hung in the exhibition space.

2) New ways of representing the world was realized through the unique still images that Clive collected and the sound of the mill and cane fields that I recorded and the way in which we combined these elements.

3) New relationships between subjects (users and consumers) and media technologies was exemplified by the combination of the visual and audio aspects of the sugar mill as broadcast on youtube (see link http://www.youtube.com/watch? $v=x W Q j B b 4 t A J 4)$ ).

4) New experiences of the relationship between embodiment, identity and community was portrayed by the inclusion of Phillip Miskin the general manager of the south Johnstone mill who opened the exhibition and the mill workers themselves who through the experience made connections with communities outside of their own, in this case two researchers from James Cook University.

Autoethnography in the context of "Sweet Crush":

Autoethnography is a research approach employed in several disciplines such as sociology, education and anthropology (re: Anderson 2006; Ellis 2000; Etherington 2004; Reed-Danahay 1997; Roth 2005). As McIlveen states: The defining feature of autoethnography is that it entails the scientist or practitioner performing narrative analysis pertaining to himself or herself as intimately related to a particular phenomenon (McIlveen 2008).

Autoethnography is a form or method of social research that explores the researcher's personal experience and connects this autobiographical story to wider cultural, political, and social meanings and understandings. I have great deal of experience with ethnographic research in my ethnomusicological fieldwork conducted during my doctoral research in West Sumatra. Autoethnography differs from ethnography - a qualitative research method in which a researcher uses participant observation and interviews in order to gain a deeper understanding of a group's culture - in that autoethnography focuses on the writer's subjective experience rather than the beliefs and practices of others. In the context of Sweet Crush this is exemplified not only by the description of events and the processes of creating the soundtrack but also my reflections on the experience of interacting with the mill workers and the mill environment as well as the collaboration process with my colleague Clive Hutchison.

\section{Outline of article}

This article begins with a brief background of the South Johnston Sugar Mill and region. This followed by an auto-ethnographic account of the process I used to create the soundtrack for Sweet Crush and the collaborative process with the photographer from my point of view. The narrative then explores the connections between the project and the workers at the mill and leads to some concluding thoughts.

\section{Background: South Johnstone Mill and Region}


The South Johnstone website gives the following description of South Johnstone: A rural town of about 480 people is $10 \mathrm{~km}$ south of Innisfail and $80 \mathrm{~km}$ southeast of Cairns. It is on the South Johnstone River, which was named by the explorer, George Dalrymple, in 1873 after Robert Johnstone, sub-inspector of the native police. Dalrymple had also been a sub-inspector before embarking on the Government directed exploration of north Queensland. About ten years after the first sugar cane was grown at Innisfail a syndicate financed a plantation on the South Johnstone River (Queensland 2011).

The population of about 482 in 2006 is significantly down from the peak of 918 in 1947 and still lower than the 1986 figure of 609. The Canecutter Way website gives the following description of the demographics of the area:

The region's settlers were culturally diverse. The first group were Anglo-Celtic, but were outnumbered by Aboriginals, South Sea Islanders, Torres Strait Islanders and Chinese. Now the area is also home to descendents of later migration from Italy, Spain, Greece, Malta, Yugoslavia, India, Pakistan, Philippines and Hmong refugees from Laos. This multi-cultural community continues to welcome people from many places around the world (Unknown 1999).

The sugar mill at South Johnstone is the outcome of established sugar plantations in the region. Alan Hudson has written a book about the South Johnstone Mill titled "Sweet Success". The main focus of the book was firstly a "hostile takeover bid by Tate \& Lyle for South Johnstone Mill Limited" in 1994 and secondly the history of the mill starting in October 1916 (Hudson 1995). This book was proudly handed to us when we arrived at the mill by Mr. Miskin and has provided some valuable insights in the ongoing daily workings of a sugar mill.

For it's first decade the Queensland government supported the mill financially. By 1927 the local growers tired of the way government managed the mill organized an association to buy the mill. Over the years the mill has experienced the normal ups and downs of a business but also strikes which resulted in a "death on a picket line". The influx of immigration included Chinese, Italians, Germans, Yugoslavs, Greeks, Spaniards and Maltese backgrounds and which lead to the secret "Black Hand" society much like the Mafioso of Italy and the United States.

There was a period where men from the South Pacific and Torres Strait came to North Queensland to 'cut cane' and work mostly as indentured laborers. This led to large communities of 'South Islanders and Torres Strait Islanders relocated to North Queensland (Salisbury 2009). Mechanization eliminated the need for cane cutters and the development of an extensive railway system helped to bring the mill back into economic prosperity (Hudson 1995).

\section{The Process (Soundtrack)}

To create the sound track for Sweet Crush, I faced several problems that needed to be resolved.

1. What equipment to use to get the best quality sounds

2. What sounds to capture and how to use these sounds effectively

3. How to design and construct the soundtrack successfully 
4. What software programs to utilize to get the best results

5. How to synchronize the soundtrack to the visual images

In order to capture the sound I needed for the project I used a Tascam DA-P1 Digital Audio Tape recorder. The reason for this was to capture the cleanest signal source possible and to be able to manipulate the audio material with digital technology losing the least amount of signal in the transfer process. My objective was to produce a musical soundscape that used only the sounds of the cane fields and sugar mill as the source with no synthesized or musical instruments (electronic or otherwise) utilized to create the soundtrack. My reasoning for this approach was so the sonic ambience of the mill would be emphasized instead of a music instrument sounds or a synthesized instrument sounds. This type of method is along the lines that were pioneered by sound artists such as Pierre Schaeffer who coined the term Musique Concrète: Concrete music, music prepared from recorded sounds, either natural (e.g. birdsong) or man-made (traffic, instr. etc.). Term originated by Pierre Schaeffer in 1948 to differentiate between music assembled from concrete sound objects and music based on the abstract medium of notation (Unknown accessed October 27, 2011).

This approach was also expressed by Jean Epstein when he described the possibility of creating dissonances, melodies, symphonies of noise and chords through the 'transposition of natural sounds' (Battier 2007).

The type of recording process I used can also be likened to the process of biologists taking samples of local flora and fauna because I ultimately used small snippets of digital audio information to analyze the audio environment and then to manipulate the sound to create a new version of it. This follows the description of Musique Concrète given by Jean de Reydellet when he states: In contrast, the new concrete music begins with a collection of synthetic and sampled materials. After a period of experimentation, the composer develops a sketch, which is refined to arrive at a composition (Reydellet 1996).

Once I had the samples of wind in the cane fields, cane trains passing by on the tracks in the fields and yards in the sugar mill and machinery in the mill, I was ready to construct the soundtrack for Sweet Crush. The soundtrack has two distinct sections with the first section a more authentic use of music concrete using train sounds, drill sounds, the dropping of a metal tool on a cement floor in a alternating rhythmic fashion in order to create a sense of the mill environment but with a rhythmic pulse. The second section has a background track of the mill machines and foreground track of a music score using machine sounds as the sonic source. I decided to use both approaches in order to breakup the sound track and give the composition more variety.

The first challenge that I faced was how to separate all of the sounds I recorded into separate distinct sounds that I could then manipulate with various music software programs. One of the most powerful programs in music software technology is the audio recording program ProTools. This program is an industry standard that is used extensively in recording studios worldwide. It allows the user to have multiple streams or tracks of audio information that can be then mixed or balanced, such as volume or loudness, between the tracks. 
In order to produce this I first imported the various samples of machine sounds such as the low rumble of a diesel engine or the high-pitched hiss of compressed air as a continuous recording into a software program called ProTools. In ProTools I was then able to separate the various individual sounds into discrete sound waves or sound files which I then exported out of the ProTools program in order to be able to use these files in other software programs. By the end of this process I had compiled several hundred samples so this needed to be culled down to a manageable selection.

During this part of the process I was constantly reflecting on how these sounds might be utilized in a musical sense. My initial intention was to create a musical score that was more based in contemporary music rather than classical music so the emphasis would be a modern rhythm section more specifically drums set and bass. This was due in part to the natural environment at the mill which of course is a very industrial setting and I noticed as I recorded the various sounds an environment with a pulse or tempo due in part to the percussive sounds of the machinery. This idea of a rhythmical relationship of workers and the environment is discuss later in this paper under the concept of entrainment. After some deliberation I realized that the higher (pitched) or sounding samples would be best for creating sounds such as a cymbal or snare drum and the lower (pitched) or sounding samples would be good for creating bass drum. tom tom drums or bass line (such as a bass guitar).

After isolating the samples into the above groupings I exported the individual samples as discrete files to be use in another software program Reason. The choice of this program was due to the function in that program to create a sequence or digital (MIDI) recording. This represents events as they occur in a timeline not audio sound, as is the case when using ProTools. MIDI (musical instrument digital interface) is a music software protocol that is standard in the industry so that music equipment such as synthesizers, samplers, and software programs can all communicate and transfer information between programs and equipment.

However before I imported the samples into Reason I decided to compose the score using another software program that allows me to notate the music into a musical score. As I am composer I am most comfortable using Sibelius, a notation program, to construct my music ideas into a musical score. This allows me to hear and see the inter-relationships between the various parts or lines of music. Sibelius and Finale are the two most widely used music notation programs used by composers, songwriters and music educators today.

As I had already decided to create a contemporary musical score I started with percussion sounds such as cymbals, snare drum, tom tom drums and bass drum. Each of these sound were represented on a separate line so I could transfer each line discretely to the sequencing program Reason. In addition I added a bass line track as well to give some harmonic definition to the soundtrack. During this part of the process the age-old dilemmas of composition continued to come up. How was I to keep the music fresh and interesting? This has to do with theme and variation in which the composer uses techniques to manipulate the basic music ideas to create an ongoing evolution of the music. In this case it was manifest through the increase of rhythmical activity and a decrease of rhythmical activity in a cyclical fashion. This can be produced by doubling the amount of attacks or hits within a period of time, 
usually designated by a grouping called a measure or bar at a particular speed or rate, in each percussion sound to increase the sense of rhythmical activity.

After completing the score I was then able to export this information as a MIDI file into Reason. This represented a nearing of the final stages in creating the soundtrack for Sweet Crush. In Reason my task was to transform the samples I had created in ProTools and link them with the MIDI information created in Sibelius. In that program I was able to manipulate the diesel sound into a bass drum sound and the compressed air sound into a cymbal sound. In all I utilized several of the machine sounds to produce Hi Hat cymbals, Bass Drum, Snare Drum, Hi Tom and Mid Tom Drums as well as a Bass line (as in Bass Guitar). This was achieved by the manipulation of each sound using an envelope filter built into the program.

The first step was to modify the sounds using the envelope filters in the sampler. Reason comes packaged with two samplers (a device that uses sound wave files to create sound) and several synthesizers (devices that create sounds by means of tone generators). An envelope filter modifies the sound by controlling the Attack (or how hard or soft the sound is), Delay (how long or short the sound takes to become full), Sustain (how long or short the sound remains full) and Release (how slow or fast the sound disappears). The acronym for this filter is ADSR and is utilized in most music software in some fashion.

As I was modifying each sound it became clear to me that the listener would not be able to perceive where these sound came from. In other words how the sound of compressed air evolved to become a cymbal sound. To emphasis this I changed each sound in a progressive fashion over the development of the track so that you can hear the compressed air sound become a cymbal sound. In order to resolve this problem I hit upon the idea of making each sound change gradually so I had to learn how to use the program's automated feature. This is a technology used by studios in particular where there is a MIDI signal to gradually change from one setting to another. Once I had resolved this issue I then linked the sound with the sequenced tracks created when I imported the Sibelius score into the Reason program.

After completing this step in Reason I was then able to export this information as an audio file (song file) as an output. This enabled me to then use the modified sounds I had developed in Reason linked with the music score I created in Sibelius and import them back into ProTools to blend them together as a cohesive soundtrack. This brought to the final stages of assembling the soundtrack. After listening to the various sounds synchronized to the score it seemed as though something was missing. After several experiments and trying various solutions I realized that the real factory sounds were missing. In other words I had been too clever and in some ways had defeated my purpose of using Musique Concrète concepts by making the soundtrack too musical.

This is when I started working with the idea of first having just sounds such as the wind in the cane fields and trains passing by along with mill sounds such as a metal bar dropping on the ground or a drill sound or the sound of a train coupling assembled in a unique sequence connected by rhythmical motives or patterns. This part became the introduction or beginning section of the soundtrack. This line of reasoning also got me thinking of how to blend the machinery sounds with the composed and 
modified sound. I ultimately built an additional track that just had the machinery sound flowing from one sound to another. In addition to this I decided at a point midway in the piece to bring up the volume of the machinery and lower the volume of the music track in order to create a bit of a competition between the two distinct tracks. The music soundtrack then comes back up in volume and the whole piece ends as it started with wind and trains riding off into the distance.

As can be seen there were many steps involved with the final output of the video Sweet Crush and the use of very sophisticated software programs to manipulate the original data or information we gathered. It is this high level of technology and the transformation of normal everyday events into new expressions that are at the heart of New Media.

\section{The Process (Collaboration)}

As Clive produced the image montage we would exchange versions and give suggestions to each other as to how to best use the ideas we were generating. At first this was a bit cumbersome as he would have ideas and then I would have ideas and we just couldn't seem to agree on what approach to use to get the most effective blend of visual and audio information. It finally became clear that the visual images needed to be in the form of a video in order to create a timeline for the music to be synchronized with. This is when we decided that Final Cut Pro would be the best software program to accomplish our objectives. After several drafts or versions had been generated I finalized the soundtrack. This gave Clive the timeline to synchronize the photomontage. The approached used here is the same strategy that is employed in a music video that you might see on MTV. That is, the visual imagery is aligned with the musical content which sets the pulse or tempo of the piece. This is in contrast to the process employed when scoring a film where the visual footage determines the timings or pace and referencing of the music soundtrack.

\section{The Embedded Meaning in Everyday Events of the Mill}

One of the interesting aspects of the mill that I observed was a seemingly natural rhythm or pulse to all of the activity that took place in the milling process both in the actions and sound of the machinery and human workforce. This led me to look into the concept of entrainment, a concept I learn from my ethnomusicology training and was first introduced to by my readings of John Blacking. According to Blacking, "bodily resonance" (which he also referred to as "bodily empathy") is the sensation or awareness of synchronizing with the physical movements of others in a musical situation. Blacking described this as "the experience of 'falling into phase' that players shared" (Blacking 1983). "Entrainment is a phenomenon in which two or more independent rhythmic processes synchronize with each other" (Clayton 2004). I found that there are many areas of research, physical or biological, psychological, cognitive etc. that have delved into the effect of entrainment on human physiology: Examples of endogenous or naturally occurring rhythms within the human body include the heart beat, blood circulation, respiration, locomotion, eyes blinking, secretion of hormones, female menstrual cycles, and many others (Clayton 2004).

This establishes that the human body is in itself an internal collection of rhythmic processes. As Clayton, Sager and Will state: 
Entrainment is fundamental then, not just to coordinate with others, but even to perceive, react to, and enjoy music. Music, as an external oscillator entraining our internal oscillators, has the potential to affect not only our sense of time but also our sense of being in the world (Clayton 2004).

The connection in this instance is not musical cues but mechanical cues so I recorded the various mechanical rhythms that the mill machinery produced. The soundtrack that I eventually produced contained many of the machine sounds as a base track over which I composed a music track utilizing the machine sounds as the initial audio source. The machine track has its own unique rhythm that underlies the overall pulse and tempo of the piece.

\section{Conclusions}

The experience that Clive and I had in the data collection was unique due to the industrial context in which occurred. The workers at the site were, to say the least, skeptical of our intentions to capture their environment for a research project by two lecturers from James Cook University. In spite of this all of the people we encountered were very helpful and had an obvious pride in what they did at the mill. The supervisor Philip Miskin traveled to Townsville to open up the exhibition at Umbrella Studio and gave a heartfelt speech. Philip expressed his amazement at the ways in which the audience attending the opening was delighted to experience a new perspective of the sugar industry and how different the mill looked in the exhibition space at Umbrella Studio Contemporary Arts. This project made a unique connection with an industry that has resonance with much of North Queensland and many contributing industries that are related in some fashion. The way in which the video expresses the unique interaction of human, plant and machine demonstrates the interconnectivity human endeavor in an environment and context.

The communities involved are small tight knit groups of people that share common values and goals and live with the ebb and flow of an industry that is reliant on natural conditions such as weather, pestilence and plant diseases. In addition to these issues is the current world situation or factors such as the price of sugar at the time or being undersold by competitors and more local circumstance such as the stability and viability of the mill or parent company. It is with all of these factors that we felt encouraged to show the South Johnstone mill in a new and unique light.

\section{Works Cited}

Anderson, L. (2006). "Analytical autoethnography." Journal of Contemporary Ethnography 35(4): 373-395.

Battier, M. (2007). "What the GRM brought to music: from musique concète to acousmatic music." Organized Sound 12: 189-202. 
Blacking, J. (1983). The concept of identity and folk concepts of self: A Venda case study. Identity: personal and socio-cultural. A. Jacobson-Widding. Stockholm, Almqvist and Wiksell: 47-65.

Clayton, M. S., R.; Will, U. (2004). "In time with the music: The concept of entraiment and its significance for ethnomusicology." ESEM Counterpoint 1: $1-82$.

Ellis, C. B., A. P. (2000). Autoethnography, personal narrative, reflexivity: Researcher as subject. Newbury Park, CA, Sage.

Etherington, K. (2004). Becoming a reflexive researcher: Using our selves in research. London, Jessica Kingsley Publishers.

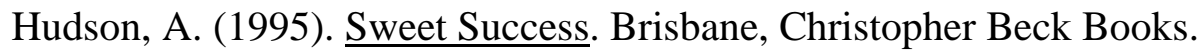

Lister, M., Dovey, J., Giddings, S., Grant, I., \& Kelly K. (2009). New Media: a critical introduction. London and New York, Routledge, Taylor and Francis Group.

McIlveen, P. (2008). "Autoethnography as a method for reflexive research and practice in vocational psychology." Australian Journal of Career Development 17(2): 13-20.

Queensland, C. f. t. G. o. (2011). "South Johnstone." Retrieved 12/10/2011, 2011, from http://queenslandplaces.com.au/south-johnstone.

Reed-Danahay, D. E. (1997). Introduction. Auto/Ethnography. Rewriting the self and the social. D. E. Reed-Danahay. Berg, Oxford: 1-17.

Reydellet, J. d. (1996). "Pierre Schaeffer, 1910-1995: The founder of 'Musique Concrete'." Computer Music Journal no. 2(Summer): 10-11.

Roth, W. M. (2005). Auto/biography and auto/ethnography: Finding the generalized other in the self. Auto/biography and auto/wthnography: Praxis of research method. W. M. Roth. Rotterdam, Sense Publishers: 3-16.

Salisbury, D. (2009). Railway Songs: The Diaspora of Eastern Torres Strait Islander music as a Reflection of People, identity and Place. Musical Islands:

Exploring Connections between Music, Place and Research. B. B. Mackinlay. newcastle, Cambridge Scholars Publishing: 94-188.

Unknown (1999). "History of the Canecutter Way." Retrieved 19/10/2011, 2011, from http://www.canecutterway.com.au/history.html.

Unknown (accessed October 27, 2011). Musique Concrète. The Oxford Dictionary of Music. M. Kennedy, Oxford Music Online. 